\title{
The geography of development in Latin America and the Caribbean: towards a new multidimensional taxonomy of the Sustainable Development Goals
}

\author{
Sergio Tezanos ${ }^{1}$
}

\begin{abstract}
The Latin America and the Caribbean region has an ambiguous place in the new geography of development: while it is a predominantly middle-income region, it is home to no more than 3\% of the world's poor population. Consequently, there is a risk that the international community will (mis)interpret this situation as meaning that the region need not be prioritized in the 2030 Agenda for Sustainable Development. Nonetheless, the Sustainable Development Goals are not merely a strategy to combat economic poverty, but also a multidimensional strategy that defines a complex world map of priorities. This article develops a multidimensional taxonomy that addresses the fundamental dimensions of sustainable human development, beyond classifications based exclusively on per capita income. Cluster analysis is used to identify the different challenges faced by Latin American and Caribbean countries and to provide guidance for international cooperation policies.
\end{abstract}

\section{Keywords}

2030 Agenda for Sustainable Development, Sustainable Development Goals, poverty mitigation, economic development, social development, classification, development indicators, Latin America and the Caribbean

JEL classification

F35, O19, I30, C5

Author

Sergio Tezanos Vásquez is a Professor in the Economics Department of the Faculty of Economic and Business Sciences of the University of Cantabria. Email: tezanoss@unican.es.

The author thanks José Antonio Sanahuja, Alejandra Kern, Daniela Perrotta, Ainoa Quiñones and an anonymous CEPAL Review referee for their valuable comments and suggestions. 


\section{Introduction}

The Sustainable Development Goals (SDGs) have begun life in a world in which one in eight people survive on daily incomes of less than US\$1.25 in purchasing power parity (PPP) terms. So, achieving the formidable goal of eradicating extreme poverty by 2030 means addressing the privations of over 800 million people.

Given this challenge, how important is Latin America and the Caribbean in the global strategy to eradicate poverty? The region, on aggregate, "successfully" attained the Millennium Development Goal (MDG) of halving extreme poverty, by cutting its poverty rate by almost 8 percentage points (from the 12.5\% recorded in 1990 to 4.6\% today) and by freeing almost 25 million Latin American and Caribbean people from poverty. Having overcome this first test, the region now faces the (probably more complicated) challenge of eliminating the remaining pockets of poverty over the next 15 years, which affect another 30 million. $^{2}$

Although the number living in poverty in the region is large in absolute terms, the fact is that Latin American and Caribbean countries account for "only" 3\% of the poor who inhabit the planet (see table 1). By contrast, over $80 \%$ of the world's poor live in the sub-Saharan Africa and South Asia regions; so to end poverty everywhere - as dictated by the first Sustainable Development Goalinternational cooperation policies should prioritize those regions.

Table 1

Distribution of world poverty by regions, $2011^{\mathrm{a}}$

(Percentages and millions of persons)

\begin{tabular}{lccrrrr}
\hline & $\begin{array}{c}\text { Poverty rate } \\
\text { (percentages) }\end{array}$ & $\begin{array}{c}\text { Poverty gap } \\
\text { (percentages) }\end{array}$ & $\begin{array}{c}\text { Share of } \\
\text { world poverty } \\
\text { (percentages) }\end{array}$ & $\begin{array}{c}\text { No. of poor } \\
\text { (millions) }\end{array}$ & $\begin{array}{c}\text { Population } \\
\text { (millions) }\end{array}$ & $\begin{array}{c}\text { Coverage } \\
\text { of the study } \\
\text { (percentages) }\end{array}$ \\
\hline East Asia and the Pacific & 7.93 & 1.56 & 15.86 & 160.76 & 2027.27 & 92.90 \\
\hline Europe and Central Asia & 0.49 & 0.14 & 0.23 & 2.35 & 479.13 & 89.00 \\
\hline Latin America and the Caribbean & 4.63 & 2.17 & 3.00 & 30.44 & 657.45 & 99.10 \\
\hline Middle East and North Africa & 1.69 & 0.35 & 0.56 & 5.64 & 333.78 & 15.70 \\
\hline South Asia & 24.50 & 5.16 & 39.36 & 398.95 & 1628.38 & 98.20 \\
\hline Sub-Saharan Africa & 46.81 & 19.18 & 40.99 & 415.40 & 887.43 & 67.50 \\
\hline Total & 16.98 & 5.05 & 100.00 & 1013.54 & 5952.76 & 86.50 \\
\hline
\end{tabular}

Source: Prepared by the author, on the basis of data from World Bank, "PovcalNet: An Online Analysis Tool for Global Poverty Monitoring", 2016 [online] http://iresearch.worldbank.org/PovcalNet/index.htm?0,0.

a Poverty line: income less than US\$1.25 dollars per day in purchasing power parity (PPP) terms.

Nonetheless, the Sustainable Development Goals are more than just a strategy to combat economic poverty; they also include a broad range of universal sustainable human development targets that define a complex global map of priorities. ${ }^{3}$ In order to help identify these polyhedral priorities and steer international cooperation policies, various multilateral organizations have constructed international classifications that group countries according to their development challenges. Curiously, the most widely used classification is actually the most simplistic one: the World Bank's annual per capita income ranking. Although simplicity is its main advantage, the fact is that this classification cannot be used to explain the geography of development in the twenty-first century. According to this classification, most of the world's poor are no longer in lower-income countries; roughly three quarters of them live in the

2 Author's calculation using disaggregated data on extreme poverty in 2011 from the 25 countries of Latin America and the Caribbean included in the PovcalNet database (World Bank, 2016b). This figure will clearly be affected by the demographic growth of the poor population by 2030.

3 For an extensive review of the strategic scope and geographical connotations of the new Sustainable Development Goals, see Sanahuja and Tezanos (2017). 
pockets of poverty that persist in the middle-income population giants (such as Brazil, China, India, Indonesia, Nigeria and Pakistan). ${ }^{4}$

The location of Latin America and the Caribbean in this new geography of development is, therefore, ambiguous: it is a region in which middle-income countries predominate, but it hardly participates in global poverty. This may be (mis)interpreted by the international community as meaning that the region need not be prioritized in relation to the Sustainable Development Goals - as also happened with their Millennium Development Goal predecessors. As the traditional income classification hardly provides any relevant information on the challenges of regional development, new multidimensional taxonomies, which are more complex and revealing, are needed to shed light on the dissimilar development challenges facing the Latin American and Caribbean countries and to guide international cooperation policies.

This article develops an alternative classification of the countries of Latin America and the Caribbean that goes beyond the traditional income criterion and instead addresses the three dimensions of sustainable development that structure the 2030 Agenda for Sustainable Development (economic development, social inclusion and environmental sustainability), plus the "essential element" of good governance. Following this introduction, section II reviews the international development classifications published by the World Bank, the Organization for Economic Cooperation and Development (OECD) and the United Nations Development Programme (UNDP). Section III proposes a multidimensional taxonomy of the development of Latin American and the Caribbean countries, which includes the four dimensions of sustainable development considered in this article. Cluster analysis is used to classify and characterize three groups of countries, in which the development profiles are similar within each group but dissimilar between them, while also identifying three other countries with unique development challenges that do not resemble those of any of the three groups. The article concludes by summarizing the main results of the classification and the analysis of its relevance for international development policies in this region.

\section{Latin America and the Caribbean in international development classifications}

It is not easy to classify countries by development level, firstly because the definition of "development" itself is complex and multidimensional. Secondly, the fact that the socioeconomic realities of the different countries are highly diverse and changing makes it difficult to perform universally valid and stable analyses over time. As Nielsen (2013) points out, there is no generally accepted classification criterion - whether based on development theory or based on an objective benchmark. Despite these difficulties, development classifications have important analytical and operational potentials (Tezanos and Sumner, 2013).

In terms of analytics, development taxonomies serve to simplify a complex and diverse world by identifying groups of countries that share similar development features. Classifications of this type are common in different domains of knowledge (such as biology, medicine, philosophy, international relations and economics). In the case of development studies, which is a multidisciplinary knowledge domain, country classifications serve both to establish the main differences (and similarities) between countries in terms of development outcomes, and to study the dynamics of progress through time.

\footnotetext{
4 For reviews of the debate on the new geography of poverty, see Sumner (2012) and Sanahuja (2013).
} 
In relation to operational potentials, international classifications are useful for development agencies, since they make it easier to establish criteria for allocating resources geographically and for designing differentiated cooperation policies that take account of the specific development challenges of the recipient countries. For example, as discussed below, the eligibility of countries for official development assistance (ODA) is based on a development taxonomy.

Nonetheless, there are several international development classifications that use different criteria to define a type of global development threshold that distinguishes between developed and developing countries. The three most influential classifications are those of the World Bank, OECD and UNDP.

Since 1978, the World Bank has published a classification of countries according to their per capita income (estimated by per capita gross national product (GNP) calculated using the Atlas method). Although the World Bank itself recognizes that development is more than just income, it does consider that GNP per capita has proven a useful and simple indicator that is highly correlated with other non-monetary measures of the quality of life, such as life expectancy at birth, and the infant mortality and school enrolment rates (World Bank, undated). Thus, in the latest update, the World Bank classifies countries into four income groups: low (with a GNP per capita of less than US\$1,005 in 2016); lower-middle (with a per capita GNP of between US\$1,006 and US\$3,955); upper-middle (US\$3,956 to US\$12,235); and high (GNP per capita of US\$12,236 or more) (World Bank, 2018).

In contrast, the OECD Development Assistance Committee (DAC) distinguishes two groups of countries to provide an objective criterion for granting ODA. These are developed countries (which generally correspond to the high-income countries in the World Bank classification) and developing countries (low, lower-middle, and upper-middle income according to the World Bank). The latter are the potential recipients of ODA (DAC, 2014).

Lastly, UNDP classifies countries according to their human development levels by computing the synthetic Human Development Index (HDI), which partially reflects the multidimensional nature of the human development concept. Specifically, HDI summarizes three dimensions of development: longevity, education and purchasing power. ${ }^{5}$ The calculation of the corresponding HDI enables each country to be classified on four levels of human development (UNDP, 2015): very high (HDI higher than 0.8 in 2014), high ( $\mathrm{HDI}$ between 0.8 and 0.7), medium (HDI from 0.55 to 0.7 ) and low (HDI below 0.55).

To what extent do these three development classifications coincide in the context of Latin America and the Caribbean? Table 2 shows that of the region's 41 countries, 17 are developed (in other words high-income countries), while the remaining 24 are developing. The latter group contains just one low-income country (Haiti), along with six lower-middle and 17 upper-middle-income ones. In HDI terms, the region has two countries rated very high, 23 high, seven medium and one low (UNDP does not classify the remaining eight countries). In short, Latin America and the Caribbean is a region dominated by countries of upper-middle income and high human development.

Although the lists are broadly consistent with each other, there are several discrepancies between the World Bank and DAC classifications by per capita income and that based on human development (UNDP). Only two of the 17 high-income countries (Argentina and Chile) and none of the 17 uppermiddle-income countries are rated at the very high human development level. Nonetheless, two upper-middle-income countries (Brazil and Panama) are very close to surpassing the per capita GNP threshold of US\$12,736; accordingly, they will likely be the next two Latin American countries to join the high-income group (developed countries), according to the World Bank and DAC classifications, even though they may not attain the highest level of human development according to UNDP.

\footnotetext{
5 In fact, the purchasing power dimension of HDI is also calculated using an indicator of per capita income (GDP per capita in PPP terms), which produces a degree of overlap between the three development classifications.
} 
Table 2

Various classifications of the countries of Latin America and the Caribbean

\begin{tabular}{|c|c|c|c|c|}
\hline & & $\begin{array}{c}\text { World Bank } \\
\text { (per capita GNP bracket) }\end{array}$ & $\begin{array}{l}\text { United Nations Development } \\
\text { Programme (UNDP) } \\
\text { (HDI group) }\end{array}$ & $\begin{array}{c}\text { Development Assistance } \\
\text { Committee (DAC) } \\
\text { (developed/developing } \\
\text { country) }\end{array}$ \\
\hline 1. & Antigua and Barbuda ${ }^{\mathrm{a}}$ & High & High & Developed \\
\hline 2. & Argentinab $^{b}$ & High & Very high & Developed \\
\hline 3. & Aruba & High & .. & Developed \\
\hline 4. & Bahamas & High & High & Developed \\
\hline 5. & Barbados & High & High & Developed \\
\hline 6. & Belize & Upper-middle & High & Developing \\
\hline 7. & Bolivia (Plurinational State of) & Lower-middle & Medium & Developing \\
\hline 8. & Brazil & Upper-middle & High & Developing \\
\hline 9. & Chile $^{\mathrm{a}}$ & High & Very high & Developed \\
\hline 10. & Colombia & Upper-middle & High & Developing \\
\hline 11. & Costa Rica & Upper-middle & High & Developing \\
\hline 12. & Cuba & Upper-middle & High & Developing \\
\hline 13. & Curaçao & High & .. & Developed \\
\hline 14. & Dominica & Upper-middle & High & Developing \\
\hline 15. & Ecuador & Upper-middle & High & Developing \\
\hline 16. & El Salvador & Lower-middle & Medium & Developing \\
\hline 17. & Granada & Upper-middle & High & Developing \\
\hline 18. & Guatemala & Lower-middle & Medium & Developing \\
\hline 19. & Guyana & Lower-middle & Medium & Developing \\
\hline 20. & Haiti & Low & Low & Developing \\
\hline 21. & Honduras & Lower-middle & Medium & Developing \\
\hline 22. & Cayman Islands & High & ... & Developed \\
\hline 23. & Turks and Caicos Islands & High & .. & Developed \\
\hline 24. & United States Virgin Islands & High & .. & Developed \\
\hline 25. & Jamaica & Upper-middle & High & Developing \\
\hline 26. & Mexico & Upper-middle & High & Developing \\
\hline 27. & Nicaragua & Lower-middle & Medium & Developing \\
\hline 28. & Panama & Upper-middle & High & Developing \\
\hline 29. & Paraguay & Upper-middle & Medium & Developing \\
\hline 30. & Peru & Upper-middle & High & Developing \\
\hline 31. & Puerto Rico & High & .. & Developed \\
\hline 32. & Dominican Republic & Upper-middle & High & Developing \\
\hline 33. & Saint Kitts and Nevis & High & High & Developed \\
\hline 34. & Saint Martin (French part) & High & .. & Developed \\
\hline 35. & Saint Martin (Dutch part) & High & .. & Developed \\
\hline 36. & Saint Lucia & Upper-middle & High & Developing \\
\hline 37. & Saint Vincent and the Grenadines & Upper-middle & High & Developing \\
\hline 38. & Suriname & Upper-middle & High & Developing \\
\hline 39. & Trinidad and Tobago & High & High & Developed \\
\hline 40. & Uruguay $^{\mathrm{a}}$ & High & High & Developed \\
\hline 41. & Venezuela (Bolivarian Republic of $)^{b}$ & High & High & Developed \\
\hline
\end{tabular}

Source:Prepared by the author, on the basis of data from World Bank, "World Development Indicators", 2016 [online] http:// databank.worldbank.org/data/home.aspx; United Nations Development Programme (UNDP), Human Development Report 2015: Work for Human Development, New York, 2015 [online] http://www.undp.org/content/undp/en/home/ librarypage/hdr/2015-human-development-report.html; and Development Assistance Committee (DAC), "DAC List of ODA Recipients 2014-2016", 2014 [online] http://www.oecd.org/dac/stats/documentupload/DAC\%20List\%20of\%20 ODA\%20Recipients\%202014\%20final.pdf.

a Antigua and Barbuda, Chile and Uruguay exceeded the high-income threshold between 2012 and 2013. According to DAC regulations, these three countries ceased to be recipients of official development assistance in 2017.

b Argentina and the Bolivarian Republic of Venezuela exceeded the high-income threshold between 2013 and 2014. Therefore, they will cease to be recipients of official development assistance as from 2018, provided they are still high-income countries at that time. 


\section{An alternative classification for Latin America and the Caribbean: taxonomy of the Sustainable Development Goals}

Once the indicative variable - or the various indicative variables - of development levels have been chosen, different procedures are used to define the country groupings. The World Bank and UNDP use an ordinal ranking. Nonetheless, this procedure does not make it possible to determine the appropriate number of groups, or where to place the thresholds that separate them. ${ }^{6}$ As will be explained later, cluster analysis offers a more nuanced and objective statistical technique than the mere ordering of a given development indicator. ${ }^{7}$

The following paragraphs make a different classification of the countries of Latin America and the Caribbean, based on the Sustainable Development Goals. Starting with the main dimensions of sustainable human development, a small set of indicators of these dimensions is then chosen to classify the countries of the region through the statistical technique of cluster analysis. A justification is then provided of the advantages of cluster analysis for establishing an international development taxonomy. Thirdly, the resulting clusters are analysed and the main development challenges characterizing each of the country groups are identified.

\section{Dimensions of the Sustainable Development Goals}

The process of producing an international classification of development starts by clearly defining the dimensions to be assessed in the classification. Given that global development agendas have the basic task of defining the international community's priority objectives, the classification is based on the main dimensions of the 2030 Agenda for Sustainable Development. This strategy of 17 major goals combines two convergent agendas: first, the human development agenda inherited from the Millennium Development Goals; and, second, the sustainable development agenda that emerged from the four conferences popularly known as Earth Summits: the United Nations Conference on the Human Environment, held in Stockholm in 1972; the United Nations Conference on Environment and Development and the United Nations Conference on Sustainable Development, held in Rio de Janeiro (Brazil) in 1992 and 2012, respectively; and the World Summit on Sustainable Development, held in Johannesburg (South Africa) in 2002.

The concept of sustainable development has evolved recently as a result of lively debate on the 2030 Agenda. The four conferences gave rise to a three-dimensional definition of sustainable development, which includes the economic, social and environmental dimensions. Nonetheless, the Open Working Group of the General Assembly on the Sustainable Development Goals (United Nations, 2014a) and the United Nations Sustainable Development Solutions Network (SDSN, 2013) proposed a four-dimensional definition that also includes good governance. This was endorsed by the United Nations Secretary General in his Synthesis Report on the Post-2015 Sustainable Development Agenda (United Nations, 2014b), which recommended integrating the "four interdependent dimensions of sustainable development" economic development (including the eradication of extreme poverty and hunger), social inclusion, environmental sustainability and good governance (which includes peace and security). Nonetheless, this four-dimensional definition did not gain the consensus of the General Assembly; so the Sustainable Development Goals as adopted finally recognize three dimensions and one essential element for sustainable development (specifically, democracy, good governance and the rule of law) (United Nations, 2015).

\footnotetext{
6 For a critique of the arbitrary way in which the World Bank and UNDP define the intervals of each group, see Nielsen (2013).

7 Earlier studies have prepared development taxonomies through cluster analysis. See the study by Tezanos and Quiñones (2012) for the middle-income countries of Latin America and the Caribbean, and the work of Tezanos and Sumner (2013 and 2016) for developing countries as a whole.
} 
Accordingly, obviating the distinction between "dimensions" and "essential element", 8 a taxonomy of the Sustainable Development Goals based on cluster analysis is constructed by assigning one of the 169 goals to each dimension, and then choosing an indicator to proxy each of these goals (see table 3).

Table 3

Dimensions of sustainable development and classification variables ${ }^{a}$

\begin{tabular}{lllll}
\hline Development dimension & SDG target & Indicator & Source & Period \\
\hline 1. Economic development & $\begin{array}{l}\text { By 2030, eradicate extreme } \\
\text { poverty for all people everywhere }\end{array}$ & $\begin{array}{l}\text { Poverty rate (US\$ 1.25 per } \\
\text { day, PPP) (percentage of } \\
\text { the population) }\end{array}$ & World Bank (2016b) & $\begin{array}{l}\text { 2012 or latest year } \\
\text { available }\end{array}$ \\
\hline 2. Social inclusion & $\begin{array}{l}\text { By 2030, progressively achieve and } \\
\text { sustain income growth of the } \\
\text { bottom 40 per cent of the } \\
\text { population at a rate higher than the } \\
\text { national average }\end{array}$ & $\begin{array}{l}\text { GDP share of the poorest } \\
\text { 40\% of the population }\end{array}$ & $\begin{array}{l}\text { ECLAC (2016) and } \\
\text { World Bank (2016a) }\end{array}$ & $\begin{array}{l}\text { 2012 or latest year } \\
\text { available }\end{array}$ \\
& & & \\
\hline 3. Environmental sustainability & $\begin{array}{l}\text { Integrate climate change measures } \\
\text { into national policies, strategies } \\
\text { and planning }\end{array}$ & $\begin{array}{lll}\text { Per capita carbon dioxide } \\
\text { emissions }\end{array}$ & ECLAC (2016) & 2010 \\
\hline 4. Good governance & $\begin{array}{l}\text { Substantially reduce corruption and } \\
\text { bribery in all their forms }\end{array}$ & Control of corruption & Kaufmann, Kraay and & 2013 \\
\hline
\end{tabular}

Source:Prepared by the author, on the basis of World Bank, "World Development Indicators", 2016 [online] http://databank. worldbank.org/data/home.aspx; "PovcalNet: An Online Analysis Tool for Global Poverty Monitoring", 2016 [online] http://iresearch.worldbank.org/PovcalNet/index.htm?0,0; Economic Commission for Latin America and the Caribbean (ECLAC), "CEPALSTAT", 2016 [online] http://estadisticas.cepal.org/cepalstat/portada.html?idioma=english; and D. Kaufmann, A. Kraay and M. Mastruzzi, "Worldwide Governance Indicators", 2014 [online] www.govindicators.org.

a Table 1 of Annex A1 displays the descriptive statistics of the variables used in the cluster analysis.

Selecting the most suitable indicators for each dimension is not an easy task, partly because the final set of Sustainable Development Goal indicators has not yet been officially approved. Moreover, as happened before with the Millennium Development Goals agenda, the Sustainable Development Goals start out within the framework of the "statistical fiction" of data availability, which, in most countries, will take several years to prepare and systematize. This will lead to an extensive initial period in which it will be virtually impossible to rigorously evaluate the progress of the agenda. Accordingly, the indicators used in this analysis have been selected on the practical (and inevitable) criterion of data availability.

\section{Statistical procedure: analysis of development clusters}

Cluster analysis makes it possible to classify a sample of heterogeneous countries in a certain number of groups, each of which is internally homogeneous in terms of the similarities between the countries comprising it. The aim of this statistical technique is to provide reasonably objective and stable classifications (Everitt and others, 2011; Mooi and Sarstedt, 2011) -objective in the sense that an analysis of the same sample of countries using the same numerical methods produces the same classification; and stable to the extent that the classification does not change when new countries or new variables are added.

Specifically, hierarchical cluster analysis makes it possible to produce a taxonomy of countries with heterogeneous development levels and divide them into a specific number of groups, so that: (i) each country belongs to one, and only one, of the groups; (ii) all countries are classified; (iii) countries in the same group are, to some degree, homogeneous; and (iv) the countries of different groups are clearly different. This type of analysis also reveals the chain-linking structure that exists between countries, which makes it easier to identify the development characteristics of each cluster.

Cluster analysis also makes it possible to resolve two intrinsic difficulties of international taxonomies. First, it is possible to identify the appropriate number of groups into which the sample should be divided. Second, as the development indicators report different values for each country,

\footnotetext{
8 Nonetheless, this apparently rhetorical distinction between dimensions and essential elements has doctrinal significance, since it lowers the ambition with which sustainable human development is conceived.
} 
the different indicators can be agglutinated to form a synthetic distribution that makes the variables easier to compare. Nonetheless, cluster analysis poses a specific difficulty when classifying countries (Nielsen, 2013): if the values of the development indicators are evenly distributed across the countries, the analysis does not make it possible to distinguish groups, even if there are marked differences between each country's indicators. As noted below, this shortcoming is not relevant for Latin America and the Caribbean, however, since the analysis clearly discerns the chain linking structure that exists between the countries and, consequently, makes it possible to identify a small number of groups.

In the present study, hierarchical clusters were analysed using the Ward method, under which the squares of the Euclidean distances between each element are calculated, and the variables to be analysed are pre-standardized to correct for differences in scale. ${ }^{9}$ The analysis covers 26 of the 41 Latin American and Caribbean countries (63.4\%), representing $88.6 \%$ of the region's population. ${ }^{10}$

Before performing the cluster analysis, a decision must be made on the most appropriate design for producing a taxonomy of Latin American and Caribbean development that is sufficiently robust and stable. This requires evaluating the five aspects listed below.

First, the appropriate number of variables that can be included in the analysis must be determined. There is no universally accepted criterion for this, although Formann (1984) proposed a simple rule: the sample size (in this case, the number of countries) must be at least equal to $2 k$, where " $k$ " represents the number of classification variables. ${ }^{11}$ Thus, with the present sample of 26 countries, no more than four variables should be used (one for each dimension of sustainable development).

Second, checks must be made to see if the variables of the analysis are highly correlated, for, if so, they would be overrepresented in the results. According to Everitt and others (2011) and Mooi and Sarstedt (2011), correlations with absolute values above 0.9 are problematic. In this particular case, there are no especially high correlations among the four classification variables. ${ }^{12}$

Third, since cluster analysis is sensitive to the presence of atypical cases, checks should be made to verify whether any of the 26 countries is especially "different". A practical tool for detecting atypical cases is the dendrogram, which graphically displays the distances at which the clusters merge. The dendrogram is read from left to right: the vertical lines represent the country groupings and their position indicates the distance at which they merge. ${ }^{13}$ Thus, the dendrogram of the 26 countries in the sample clearly identifies two atypical cases: one is Haiti (the country with the lowest per capita income), which merges at a distance of 11; and the other is Trinidad and Tobago (the country with the highest income), which merges at a distance of 13 . So, it is best to consider these two countries as unique and independent cases and apply the cluster analysis to the remaining 24.

Fourth, the optimal number of country clusters must be determined. This decision is based on the following two criteria, which indicate that the optimum number in this case is four:

9 The clustering method used is explained in Annex A2. As the variables used are expressed in different scales, they are standardized to the range [1, -1] which has proven superior to other methods in most situations (Mooi and Sarstedt, 2011). The analysis uses the IBM SPSS Statistics software.

10 The 15 countries excluded from the analysis because of a lack of information are all from the Caribbean: Cuba, Puerto Rico and 13 other Caribbean island states with populations of less than 500,000 (Antigua and Barbuda, Aruba, Bahamas, Barbados, Cayman Islands, Curaçao, Dominica, Saint Martin (Dutch part), Saint Martin (French part), Saint Kitts and Nevis, Saint Vincent and the Grenadines, Turks and Caicos Islands and the United States Virgin Islands).

${ }^{11}$ Many specialists (such as Dolnicar, 2003 and Mooi and Sarstedt, 2011) consider Formann's criterion to be unduly restrictive; and few studies in the social sciences comply with it.

${ }^{12}$ See the correlations matrix in Annex A3. The variables "Corruption control" and "Share of the poorest 40\%" have the highest correlation coefficient (0.414), but still well within the stated limit.

13 See the dendrogram in Annex A4. Note that SPSS Statistics rescales the original distances to fit a range between 0 and 25, so the last merger (which groups all countries in a single cluster) occurs at a distance of 25. 
- Clustering history shows the clusters that combine at each stage and the distance at which they merge. ${ }^{14} \mathrm{~A}$ simple scatter plot between these distances and the number of clusters reveals whether there is a break in the dotted line ("elbow") that indicates which additional combination of two clusters significantly increases the distance, in such a way that the number of clusters prior to this merger is the most appropriate. In this analysis, the scatter chart displays an "elbow" between groups four and five. ${ }^{15}$

- The dendrogram clearly differentiates four clusters of countries grouped together at a maximum distance of seven units (out of 25), while Jamaica remains the only member of the last cluster to be formed (it is, therefore, the most dissimilar country in this sample of 24). In contrast, a three-cluster grouping would increase the distance to 11 units and a grouping with a larger number would slightly reduce that distance (for example, grouping in five clusters only reduces the distance by two units).

Lastly, it is important to ascertain which variables have the greatest influence on the formation of these four groups of countries. Analysis of the variance of a factor (specifically, the cluster of membership) shows, in contrast, that the four variables used are statistically significant, at a confidence level of 99\% (see table 4). Likewise, the magnitudes of the F-statistics (which capture the relationship between inter- and intragroup variability) indicate the relevance of each of the variables in the formation of the groups, which means that the most influential variables are " $\mathrm{CO}_{2}$ per capita" and "Control of corruption", in that order.

Table 4

Variance analysis of the variables included in the cluster analysis

\begin{tabular}{|c|c|c|c|c|c|c|}
\hline & & Sum of squares & $\begin{array}{l}\text { Degrees of } \\
\text { freedom }\end{array}$ & Quadratic mean & $\mathrm{F}$ & $p$ value \\
\hline \multirow[t]{3}{*}{ Poverty rate } & Intergroup & 712.73 & 3 & 237.58 & 11.86 & 0.000 \\
\hline & Intragroup & 400.50 & 20 & 20.03 & & \\
\hline & Total & 1113.22 & 23 & & & \\
\hline \multirow{3}{*}{$\begin{array}{l}\text { Participation of the } \\
\text { poorest } 40 \%\end{array}$} & Intergroup & 58.35 & 3 & 19.45 & 5.46 & 0.007 \\
\hline & Intragroup & 71.24 & 20 & 3.56 & & \\
\hline & Total & 129.59 & 23 & & & \\
\hline \multirow[t]{3}{*}{$\mathrm{CO}_{2}$ per capita } & Intergroup & 36.37 & 3 & 12.12 & 17.16 & 0.000 \\
\hline & Intragroup & 14.13 & 20 & 0.71 & & \\
\hline & Total & 50.50 & 23 & & & \\
\hline \multirow[t]{3}{*}{ Control of corruption } & Intergroup & 8.77 & 3 & 2.92 & 16.23 & 0.000 \\
\hline & Intragroup & 3.60 & 20 & 0.18 & & \\
\hline & Total & 12.37 & 23 & & & \\
\hline
\end{tabular}

Source: Prepared by the author.

\section{Key results}

As discussed above, the cluster analysis identifies four distinct groups of Latin American and Caribbean countries, plus the two unique cases of Haiti and Trinidad and Tobago (see table 5). The first cluster (C1) contains four countries (two high income and two upper-middle income); the second (C2) has four other countries (two high income and two upper-middle); the third (C3), encompasses 15 countries (nine upper- and six lower-middle income); and the fourth (C4), has a single upper-middle income country (Jamaica). The classification of development clusters diverges sharply from the classification by per capita income levels. Thus, although the C1 and C2 clusters encompass the countries with higher incomes on average, the truth is that C3 also has two of the relatively wealthier countries (Brazil and Panama), along with a large number of countries with very low per capita incomes. Map 1 provides a simple representation of the member countries of each development cluster.

\footnotetext{
${ }^{14}$ The correlations matrix is shown in Annex A5. For example, in the first stage, Ecuador (country 9) and Guyana (country 13) merge at a distance of 0.003 . So, the conglomerate is named with the number of the first country involved in the merger (in this case, country 9, which merges again in stage 2 with country 20, Peru).

15 See the scatter chart in Annex A6.
} 
Table 5

Summary of the membership clusters of the countries of Latin America and the Caribbean

\begin{tabular}{|c|c|c|c|c|c|c|c|c|}
\hline Country ${ }^{a}$ & $\begin{array}{l}\text { Membership } \\
\text { cluster }\end{array}$ & Per capita GNP & $\begin{array}{l}\text { Per capita } \\
\text { income } \\
\text { ranking }\end{array}$ & $\begin{array}{l}\text { Per capita income } \\
\text { classificationc }^{c}\end{array}$ & $\begin{array}{l}\text { Poverty } \\
\text { rate }\end{array}$ & $\begin{array}{l}\text { Share of the } \\
\text { poorest } 40 \%\end{array}$ & $\begin{array}{l}\mathrm{CO}_{2} \text { per } \\
\text { capita }\end{array}$ & $\begin{array}{l}\text { Control } \\
\text { of } \\
\text { corruption }\end{array}$ \\
\hline 5. Chile & 1 & 15230 & 2 & High & 0.83 & 12.4 & 4.22 & 1.52 \\
\hline 25. Uruguay & 1 & 15180 & 3 & High & 0.25 & 17.2 & 1.97 & 1.34 \\
\hline 11. Granada & 1 & 7460 & 12 & Upper-middle & 2.40 & 17.0 & 2.49 & 0.41 \\
\hline 22. Saint Lucia & 1 & 7090 & 13 & Upper-middle & 11.75 & 15.1 & 2.31 & 1.17 \\
\hline $\begin{array}{l}\text { 26. Venezuela (Bolivarian } \\
\text { Republic of) }\end{array}$ & 2 & 12550 & 4 & High & 5.58 & 15.6 & 6.96 & -1.28 \\
\hline 1. Argentina & 2 & 11700 & 5 & High & 1.41 & 14.1 & 4.47 & -0.46 \\
\hline 17. Mexico & 2 & 9940 & 8 & Upper-middle & 3.26 & 12.8 & 3.91 & -0.48 \\
\hline 23. Suriname & 2 & 9260 & 10 & Upper-middle & 10.52 & 10.4 & 4.54 & -0.38 \\
\hline 4. Brazil & 3 & 11690 & 6 & Upper-middle & 4.53 & 9.8 & 2.15 & -0.12 \\
\hline 19. Panama & 3 & 10700 & 7 & Upper-middle & 3.55 & 10.6 & 2.74 & -0.36 \\
\hline 7. Costa Rica & 3 & 9550 & 9 & Upper-middle & 1.36 & 11.6 & 1.67 & 0.59 \\
\hline 6. Colombia & 3 & 7560 & 11 & Upper-middle & 4.95 & 10.6 & 1.63 & -0.44 \\
\hline 21. Peru & 3 & 6390 & 14 & Upper-middle & 2.97 & 13.4 & 1.98 & -0.44 \\
\hline 8. Dominican Republic & 3 & 5620 & 15 & Upper-middle & 2.54 & 10.8 & 2.11 & -0.85 \\
\hline 9. Ecuador & 3 & 5510 & 16 & Upper-middle & 4.04 & 13.2 & 2.26 & -0.61 \\
\hline 2. Belize & 3 & 4660 & 18 & Upper-middle & 11.29 & 11.0 & 1.35 & 0.02 \\
\hline 20. Paraguay & 3 & 4040 & 19 & Upper-middle & 4.43 & 10.0 & 0.79 & -1.04 \\
\hline 13. Guyana & 3 & 3750 & 20 & Lower-middle & 5.33 & 12.7 & 2.25 & -0.64 \\
\hline 10. El Salvador & 3 & 3720 & 21 & Lower-middle & 2.82 & 14.6 & 1.01 & -0.35 \\
\hline 12. Guatemala & 3 & 3340 & 22 & Lower-middle & 13.7 & 9.0 & 0.77 & -0.58 \\
\hline $\begin{array}{l}\text { 3. Bolivia (Plurinational } \\
\text { State of) }\end{array}$ & 3 & 2550 & 23 & Lower-middle & 6.97 & 12.2 & 1.56 & -0.59 \\
\hline 15. Honduras & 3 & 2180 & 24 & Lower-middle & 16.48 & 8.6 & 1.07 & -0.95 \\
\hline 18. Nicaragua & 3 & 1780 & 25 & Lower-middle & 6.83 & 12.8 & 0.79 & -0.73 \\
\hline 16. Jamaica & 4 & 5220 & 17 & Upper-middle & 32.49 & 14.4 & 2.61 & -0.37 \\
\hline 24. Trinidad and Tobago & $\ldots$ & 15760 & 1 & High & 1.15 & 15.8 & 37.78 & -0.35 \\
\hline 14. Haiti & $\ldots$ & 810 & 26 & Low & 51.6 & 8.6 & 0.21 & -1.15 \\
\hline
\end{tabular}

Source: Prepared by the author.

Note: Indicators related to per capita income (columns three, four and five) are included as a reference, although they are not part of the cluster analysis.

a The number that precedes each country is the same as appears in the dendrogram and in the clustering history.

b The position by income levels is computed for the 26 countries of the initial sample. The clusters are numbered in increasing order of per capita income.

c Classification by per capita income according to the latest update by the World Bank (2018).

The four clusters can be characterized comparatively in greater detail using the four indicators (see table 6). 
Map 1

Taxonomy of the Sustainable Development Goals of the countries of Latin America and the Caribbean

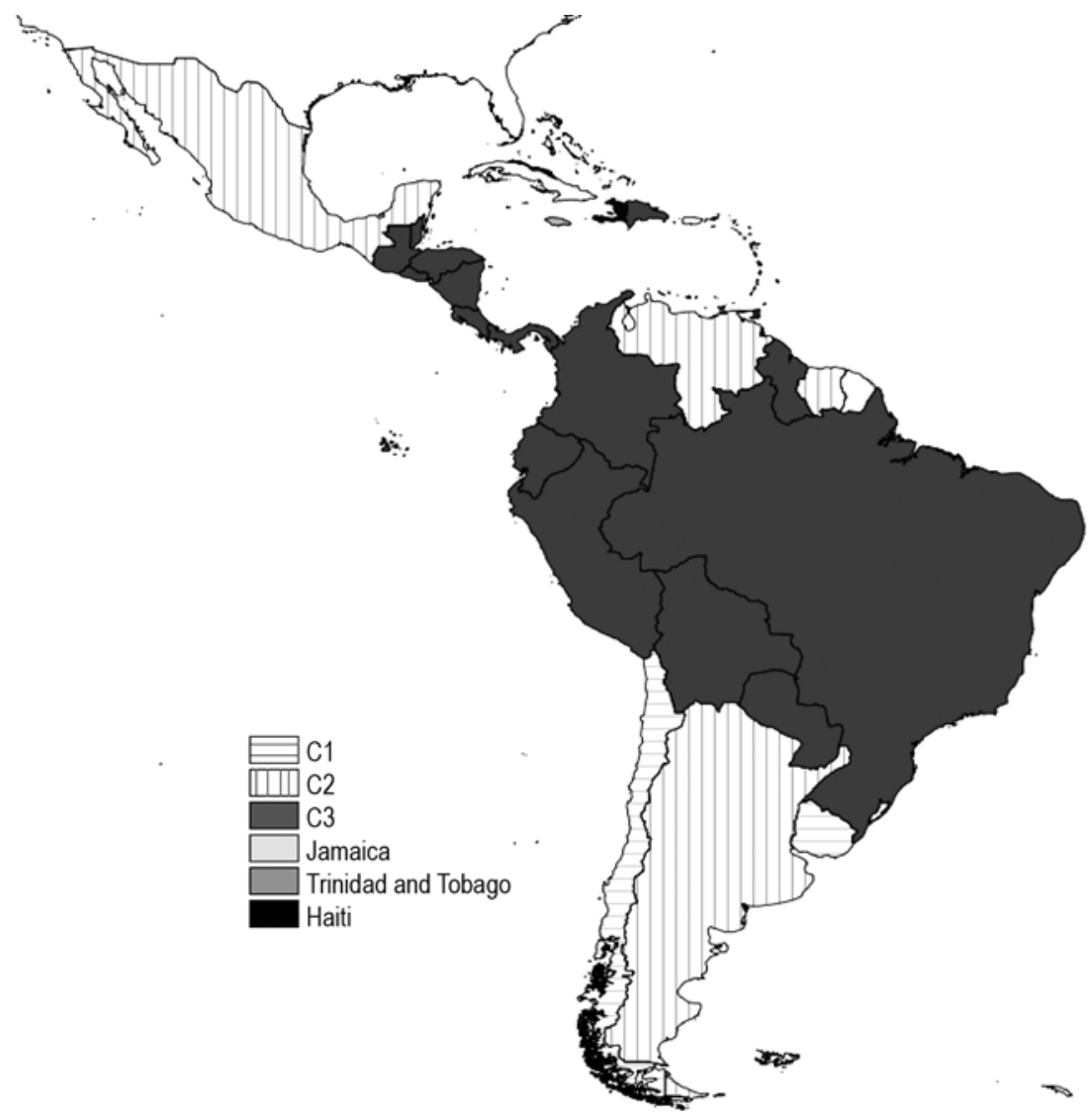

Source: Prepared by the author.

Table 6

Socioeconomic characteristics of the clusters

\begin{tabular}{|c|c|c|c|c|c|c|}
\hline & & Per capita GNP & Poverty rate & $\begin{array}{l}\text { Share of the } \\
\text { poorest } 40 \%\end{array}$ & $\mathrm{CO}_{2}$ per capita & $\begin{array}{l}\text { Control of } \\
\text { corruption }\end{array}$ \\
\hline \multirow[t]{5}{*}{$\mathrm{C} 1$} & Mean & 11240 & 3.81 & 15.43 & 2.75 & 1.11 \\
\hline & $\mathrm{N}$ & 4 & 4 & 4 & 4 & 4 \\
\hline & Std. deviation & 4581 & 5.37 & 2.23 & 1.01 & 0.49 \\
\hline & Minimum & 7090 & 0.25 & 12.40 & 1.97 & 0.41 \\
\hline & Maximum & 15230 & 11.75 & 17.20 & 4.22 & 1.52 \\
\hline \multirow[t]{5}{*}{$\mathrm{C} 2$} & Mean & 10863 & 5.19 & 13.23 & 4.97 & -0.65 \\
\hline & $\mathrm{N}$ & 4 & 4 & 4 & 4 & 4 \\
\hline & Std. deviation & 1524 & 3.94 & 2.21 & 1.36 & 0.42 \\
\hline & Minimum & 9260 & 1.41 & 10.40 & 3.91 & -1.28 \\
\hline & Maximum & 12550 & 10.52 & 15.60 & 6.96 & -0.38 \\
\hline \multirow[t]{5}{*}{ C3 } & Mean & 5536 & 6.12 & 11.39 & 1.61 & -0.47 \\
\hline & $\mathrm{N}$ & 15 & 15 & 15 & 15 & 15 \\
\hline & Std. deviation & 3095 & 4.37 & 1.73 & 0.63 & 0.41 \\
\hline & Minimum & 1780 & 1.36 & 8.60 & 0.77 & -1.04 \\
\hline & Maximum & 11690 & 16.48 & 14.60 & 2.74 & 0.59 \\
\hline C4 (Jamaica) & & 5220 & 32.49 & 14.40 & 2.61 & -0.37 \\
\hline Trinidad and Tobago & 15760 & 1.15 & 15.80 & 37.78 & -0.35 & \\
\hline
\end{tabular}


Table 6 (concluded)

\begin{tabular}{llrrrrr}
\hline & Per capita GNP & Poverty rate & $\begin{array}{c}\text { Share of the } \\
\text { poorest 40\% }\end{array}$ & $\mathrm{CO}_{2}$ per capita & $\begin{array}{c}\text { Control of } \\
\text { corruption }\end{array}$ \\
\hline Haiti & 810 & 51.60 & 8.60 & 0.21 & -1.15 \\
\hline \multirow{2}{*}{ Total (26 countries) } & Mean & 7432 & 8.19 & 12.47 & 3.68 & -0.27 \\
\cline { 2 - 7 } & $\mathrm{N}$ & 26 & 26 & 26 & 26 & 26 \\
\cline { 2 - 7 } & Std. deviation & 4387 & 11.14 & 2.50 & 7.11 & 0.73 \\
\cline { 2 - 7 } & Minimum & 810 & 0.25 & 8.60 & 0.21 & -1.28 \\
\cline { 2 - 7 } & Maximum & 15760 & 51.60 & 17.20 & 37.78 & 1.52 \\
\hline
\end{tabular}

Source: Prepared by the author.

The first cluster (C1) consists of four Latin American and Caribbean countries with high development levels, but also high per capita emissions of carbon dioxide $\left(\mathrm{CO}_{2}\right)$. They display the highest per capita income and the lowest poverty rates on average, as well as the best indicators of social inclusion and the most effective corruption controls (in fact, they are the only countries in the sample, along with Belize and Costa Rica, which display positive values in this indicator). Their high comparative development level also means that they are the group with the second highest $\mathrm{CO}_{2}$ emissions per capita (especially high in Chile). At the same time, this is the most heterogeneous cluster, as shown by the standard deviations of the indicators. Within the group, Chile and Santa Lucia (the countries with the highest and lowest income, respectively) are the most dissimilar cases and, therefore, the last two that saturate in this cluster (see again the dendrogram in Annex A4). In the case of Chile, the main difference lies in its high $\mathrm{CO}_{2}$ emissions (almost twice the average of the group in per capita terms), while Saint Lucia has the highest poverty rate (three times the group mean).

The second cluster (C2) includes four Latin American countries with intermediate levels of development and problems of corruption and pollution. On average, they have the second highest per capita income and the second lowest poverty rate. Nonetheless, this group of countries has high levels of pollution and very negative records on corruption. Although the group is relatively homogeneous, the most dissimilar country is the Bolivarian Republic of Venezuela, which, despite having the highest per capita income, also has a high poverty rate, along with the highest $\mathrm{CO}_{2}$ emissions and the highest levels of corruption.

The third cluster (C3) is the largest (15 countries) and includes Latin American and Caribbean countries with lower levels of development and problems of poverty, inequality and corruption. This group has the second lowest per capita income and the second highest poverty rate, as well as the greatest economic inequality and the worst corruption records. In contrast, the countries in this group are the least polluting in the sample in per capita terms. The main differences within this group are in their poverty rates: three Central American countries (Belize, Guatemala and Honduras) have poverty rates above $11 \%$, while Costa Rica has a rate below $2 \%$.

In addition to these three groups, the analysis identifies three "unique" countries that warrant separate analysis. The first of these is Jamaica, which is the only member of the fourth cluster (C4) and is unique owing to its high incidence of poverty (the second highest in the sample of 26 countries, after Haiti). On the rest of the indicators, it resembles the C2 countries; in fact, the dendrogram shows that Jamaica would be included in that group in the three-cluster solution.

That leaves the two "atypical" countries of the sample: Haiti and Trinidad and Tobago. Haiti has the worst development indicators: the lowest per capita income (almost 63\% less than the next lowest country, Honduras): the highest poverty rate (19 percentage points above that of Jamaica), the least economic participation by the poorest population group (along with Honduras) and the worst corruption record. Yet it is also the country with the lowest $\mathrm{CO}_{2}$ emissions per person -in this case followed by 
Guatemala. In contrast, Trinidad and Tobago has the highest per capita income and the third lowest poverty rate (after Uruguay and Chile) and economic inequality (after Granada and Santa Lucia). It is thus a country similar to those of cluster $\mathrm{C} 1$, except that its per capita $\mathrm{CO}_{2}$ emissions are by far the highest in Latin America and the Caribbean, which makes it an atypical case.

In relation to the regional distribution of the poor population (see table 7), as expected, most of the poor (almost 60\%) live in the countries of the largest cluster (C3), mainly due to the presence of the region's population giant, Brazil, which contributes almost half of the poor of this group and 30\% of those of Latin America and the Caribbean as a whole. The countries of cluster C2 account for $20 \%$ of the region's poor (over half of them living in Mexico). In addition, Haiti - given its very high incidence of poverty - accounts for $17 \%$ of all poor. The remaining $1 \%$ is distributed between the C1 countries and Trinidad and Tobago.

Table 7

Distribution of poverty among the clusters of Latin America and Caribbean countries (Percentages and millions of persons)

\begin{tabular}{lcccc}
\hline & $\begin{array}{c}\text { Poverty rate } \\
\text { (percentages) }\end{array}$ & $\begin{array}{c}\text { Population } \\
\text { (millions) }\end{array}$ & $\begin{array}{c}\text { Number of poor } \\
\text { (millions) }\end{array}$ & $\begin{array}{c}\text { Share of regional poverty } \\
\text { (percentages) }\end{array}$ \\
\hline C1 & 3.81 & 20.98 & 0.18 & 0.58 \\
\hline C2 & 5.19 & 187.44 & 6.06 & 19.89 \\
\hline C2 excl. Mexic0 & 5.84 & 71.48 & 2.28 & 7.48 \\
\hline C3 & 6.12 & 360.17 & 18.17 & 59.68 \\
\hline C3 excl. Brazil & 6.23 & 163.23 & 9.25 & 30.38 \\
\hline C4 (Jamaica) & 32.49 & 2.62 & 0.85 & 2.80 \\
\hline Trinidad and Tobago & 1.15 & 1.33 & 0.02 & 0.05 \\
\hline Haiti & 51.6 & 10.03 & 5.18 & 17.00 \\
\hline High-income countries & 0.74 & 22.02 & 0.17 & 0.55 \\
\hline Upper-middle-income countries & 6.84 & 498.17 & 20.17 & 66.25 \\
\hline Lower-middle-income countries & 8.08 & 52.34 & 4.93 & 16.19 \\
\hline Low-income country (Haiti) & 51.60 & 10.03 & 5.18 & 17.00 \\
\hline Not included in the analysis (15 countries) & $\ldots$ & 74.89 & $\ldots$ & $\ldots$ \\
\hline Total for Latin America and the Caribbean & 4.63 & 657.45 & 30.44 & 100.00 \\
\hline
\end{tabular}

Source: Prepared by the author.

By contrast with the previous distribution, regional poverty by income levels is more highly concentrated: two thirds of the poor are concentrated in the upper-middle income bracket (along with Brazil and Mexico); and the other third is distributed among high-, lower-middle- and low-income countries. Thus, the classification of countries by income level in Latin America and the Caribbean generates the same incongruity as at the world level: countries with the largest numbers of poor people are not the poorest (low- and lower-medium income countries in the Latin American and Caribbean context), but the upper-middle-income ones.

\section{Conclusions}

Various international organizations establish development taxonomies that are useful for guiding international development policies, by making it possible to identify groups of countries that face similar challenges. Despite the difficulties inherent in any international classification, the most widely used criterion is precisely the simplest, based solely on an indicator of per capita income, such as that used by the World Bank and DAC. Nonetheless, this classification does little to explain the geography 
of development in the twenty-first century, since most of the world's poor are no longer located in low-income countries, but in the large group of middle-income countries, which include the most heavily populated (mainly, Brazil, China, India, Indonesia, Mexico, Nigeria and Pakistan).

The position of Latin America and the Caribbean in this new geography of development is ambiguous: it is a region in which middle incomes predominate; yet it accommodates just $3 \%$ of the world's poor. As a result, there is a risk that the international community may (mis)interpret this and decide that the region need not be prioritized in the new cooperation agenda - as happened with the Millennium Development Goals.

Nonetheless, the Sustainable Development Goals are not only a strategy to combat economic poverty, but also a multidimensional strategy that defines a complex world map of priorities. In this context, given that the traditional classification of incomes provides little relevant information on the development challenges facing Latin America and the Caribbean, a multidimensional taxonomy of development needs to be designed which identifies the dissimilar challenges facing Latin American and Caribbean countries and helps guide international cooperation policies.

This article has developed an alternative taxonomy of the countries of Latin America and the Caribbean, which provides information to complement the income classification. The proposed taxonomy integrates the three dimensions and one "essential element" of sustainable development: economic development, social inclusion, environmental sustainability and good governance. The multivariate statistical technique of cluster analysis is used to define three groups of countries that have profound differences in their development levels:

- C1: Latin American and Caribbean countries with high levels of development, but also high $\mathrm{CO}_{2}$ emissions per capita (Chile, Granada, Saint Lucia and Uruguay).

- C2: Latin American countries with medium development levels and problems of corruption and pollution (Argentina, the Bolivarian Republic of Venezuela, Mexico and Suriname).

- C3: Latin American and Caribbean countries with lower levels of development and problems of poverty, inequality and corruption (Belize, Brazil, Colombia, Costa Rica, Dominican Republic, Ecuador, El Salvador, Guatemala, Guyana, Honduras, Nicaragua, Panama, Paraguay, Peru and the Plurinational State of Bolivia).

In addition to these three groups, the analysis identifies three "unique" countries:

- Jamaica, which would be in C2, if not for its high poverty rate.

- Haiti, the country of the region that faces the greatest development challenges (in terms of poverty, social inclusion and corruption).

- Trinidad and Tobago, which, despite its similarities with the C1 countries, has by far the region's highest per capita $\mathrm{CO}_{2}$ emissions.

These results indicate that - beyond unduly simple and economistic classifications, such as per capita income - there is no monotonically increasing distribution of development levels, which runs from a group of countries with the worst records on all indicators to another with better results in all of the variables. Conversely, the present multidimensional taxonomy offers more complex and nuanced groupings, which make it possible to identify both challenges and possibilities for advancement in each of the clusters.

This analysis can make a useful contribution to steering the effective management of development policies in the region, strategically oriented towards achieving specific progress objectives (the Sustainable Development Goals). Thus, the establishment of relatively homogeneous groups of countries makes it possible to exploit opportunities for cooperation in each of the clusters. In particular, classifications 
of this type would allow for peer evaluation (that is, between countries in the same group), collective advances and setbacks, and progress in designing specific development strategies for each group, which go beyond the generalist nature of universal development agendas. ${ }^{16}$

Likewise, the results of this taxonomy of the Sustainable Development Goals for Latin America and the Caribbean can also be useful for guiding South-South and triangular cooperation initiatives, by making it possible to identify both the potentialities of each group (which the countries can exploit in their roles as regional donors), and their weaknesses and development challenges (which should be addressed by the cooperative actions of other countries). In this sense, the countries offering South-South cooperation are distributed among all the development clusters; and these "diagonal" cooperation relations (neither vertical nor horizontal in terms of the donors' development levels) highlight the synergies existing in a diverse region.

Ultimately, the classifications must serve the purpose for which they were created: to facilitate understanding of a complex world and to guide the design of development policies. In the context of Latin America and the Caribbean, the changes - and complexities - of the new geography of development are such that the challenges of development can only be better understood by modifying the analytical frameworks through which the region is viewed, starting with the way countries are classified.

\section{Bibliography}

DAC (Development Assistance Committee) (2014), "DAC List of ODA Recipients 2014-2016" [online] http://www.oecd.org/dac/stats/documentupload/DAC\%20List\%20of\%20ODA\%20Recipients\%20 2014\%20final.pdf.

Dolnicar, S. (2003), "Using cluster analysis for market segmentation-typical misconceptions, established methodological weaknesses and some recommendations for improvement", Australasian Journal of Market Research, vol. 11, No. 2.

ECLAC (Economic Commission for Latin America and the Caribbean) (2016), "CEPALSTAT" [online] http:// estadisticas.cepal.org/cepalstat/portada.html?idioma=english.

Everitt, B. S. and others (2011), Cluster Analysis, Chichester, John Wiley \& Sons.

Formann, A. K. (1984), Die Latent-Class-Analyse: Einfuhrung in die Theorie und Anwendung, Weinheim, Beltz.

Kaufmann, D., A. Kraay and M. Mastruzzi (2014), "Worldwide Governance Indicators" [online] www.govindicators.org.

Mooi, E. and M. Sarstedt (2011), A Concise Guide to Market Research, Berlin, Springer-Verlag.

Nielsen, L. (2013), "How to classify countries based on their level of development", Social Indicators Research, vol. 114, No. 3, Springer.

Peña, D. (2002), Análisis de datos multivariantes, Madrid, McGraw-Hill.

Sanahuja, J. A. (2013), "Las nuevas geografías de la pobreza y la desigualdad y las metas de desarrollo global post-2015", El reto de la democracia en un mundo en cambio: respuestas políticas y sociales. Anuario 2013-2014, M. Mesa (coord.), Madrid, Centre for Peace Research and Education (CEIPAZ) [online] http:// www.ceipaz.org/images/contenido/4.Sanahuja.pdf.

Sanahuja, J. A. and S. Tezanos (2017), "Del milenio a la sostenibilidad: retos y perspectivas de la Agenda 2030 para el Desarrollo Sostenible", Política y Sociedad, vol. 54, No. 2, Madrid, Complutense University of Madrid.

SDSN (Sustainable Development Solutions Network) (2014), An Action Agenda for Sustainable Development. Report for the UN Secretary-General [online] http://unsdsn.org/wp-content/uploads/2013/06/140505An-Action-Agenda-for-Sustainable-Development.pdf.

Sneath, P. H. A. and R. R. Sokal (1973), Numerical Taxonomy, San Francisco, W. H. Freeman.

Sumner, A. (2012), "Where do the poor live?", World Development, vol. 40, No. 5, Amsterdam, Elsevier.

Tezanos, S. (2011), "Más allá de 2015: Objetivos de Desarrollo del Milenio y desafíos para la nueva agenda internacional de desarrollo", SISTEMA: Revista de Ciencias Sociales, No. 220, Madrid, Editorial Sistema.

${ }^{16}$ For a proposal of this type, see Tezanos (2011). 
Tezanos, S. and A. Quiñones (2012), "¿Países de renta media? Una taxonomía alternativa del desarrollo de América Latina y el Caribe", Revista Iberoamericana de Estudios de Desarrollo, vol. 1, No. 2 [online] http://ried.unizar.es/index.php/revista/article/viewFile/45/23.

Tezanos, S. and A. Sumner (2016), "Is the 'developing world' changing? A dynamic and multidimensional taxonomy of developing countries", The European Journal of Development Research, vol. 28, No. 5, Springer. (2013), "Revisiting the meaning of development: a multidimensional taxonomy of developing countries", The Journal of Development Studies, vol. 49, No. 12, Taylor \& Francis.

UNDP (United Nations Development Programme) (2015), Human Development Report 2015: Work for Human Development, New York [online] http://www.undp.org/content/undp/en/home/librarypage/hdr/2015human-development-report.html.

United Nations (2015), "Transforming our world: the 2030 Agenda for Sustainable Development" (A/RES/70/1), Resolution adopted by the General Assembly on 25 September 2015 [online] http://www.un.org/en/ development/desa/population/migration/generalassembly/docs/globalcompact/A_RES_70_1_E.pdf.

_ (2014a), "Report of the Open Working Group of the General Assembly on Sustainable Development Goals" (A/68/970) [online] https://undocs.org/A/68/970.

(2014b), "The road to dignity by 2030: ending poverty, transforming all lives and protecting the planet. Synthesis report of the Secretary-General on the post-2015 sustainable development agenda" (A/69/700) [online] http://www.un.org/ga/search/view_doc.asp?symbol=A/69/700\&Lang=E.

Ward, J. H. (1963), "Hierarchical groupings to optimize an objective function", Journal of the American Statistical Association, vol. 58, No. 301, Taylor \& Francis.

World Bank (2018), "World Bank Country and Lending Groups" [online] https://datahelpdesk.worldbank.org/ knowledgebase/articles/906519.

_(2016a), "How we classify countries: a short history" [online] http://data.worldbank.org/about/countryand-lending-groups.

(2016b), "World Development Indicators" [online] http://databank.worldbank.org/data/home.aspx.

_ (2016c), "PovcalNet: An Online Analysis Tool for Global Poverty Monitoring" [online] http://iresearch. worldbank.org/PovcalNet/index.htm?0,0.

_ (undated), "Why use GNI per capita to classify economies into income groupings?" [online] https:// datahelpdesk.worldbank.org/knowledgebase/articles/378831-why-use-gni-per-capita-to-classifyeconomies-into. 


\section{Annex A1}

Table A1.1

Descriptive statistics of the variables used in the analysis of clusters

\begin{tabular}{llcrrr}
\hline & No. & Minimum & Maximum & Mean & Standard deviation \\
\hline GNP per capita & 26 & 810 & 15760 & 7432.31 & 4386.83 \\
\hline Poverty rate & 26 & 0.25 & 51.60 & 8.19 & 11.14 \\
\hline Participation of the poorest 40\% & 26 & 8.60 & 17.20 & 12.47 & 2.50 \\
\hline $\mathrm{CO}_{2}$ per capita & 26 & 0.21 & 37.78 & 3.68 & 7.11 \\
\hline Corruption control & 26 & -1.28 & 1.52 & -0.27 & 0.73 \\
\hline No. valid (according to list) & 26 & & & & \\
\hline
\end{tabular}

Source: Prepared by the author.

\section{Annex A2}

\section{Clustering method}

Given the type of data used in the present analysis (four continuous variables), three clustering algorithms are possible (Everitt and others, 2011; Peña, 2002; Mooi and Sarstedt, 2011): the nearest-neighbour method, the farthest-neighbour method and Ward's method. Since there is no objective criterion for choosing the most appropriate method, the choice depends largely on ease of interpretation of the final results (Sneath and Sokal, 1973; Everitt and others, 2011; Peña, 2002; Mooi and Sarstedt, 2011).

This analysis uses the method proposed by Ward (1963), who argued that clusters should be constituted in such a way that, when merging two elements, the resulting information loss is minimal. ${ }^{17}$ To do this, the sum of the squares of the distances of each element is quantified with respect to the centroid of the cluster to which it belongs. Specifically, the method starts by calculating the vector of means of all the variables - "multivariate centroid" - for each cluster. Next, the squares of the Euclidean distances between each element and the centroids (vector of means) are calculated for all clusters. Then the distances corresponding to all the elements are summed. The general formula for Ward's distance $(W)$ is expressed as:

$$
W=\sum_{g} \sum_{i \in g}\left(x_{i g}-\bar{x}_{g}\right)^{\prime}\left(x_{i g}-\bar{x}_{g}\right)
$$

where $x_{g}$ is the mean of group $g$, and $i$ is a country belonging to that group.

For this research in particular, the Ward method and the farthest-neighbour method both provide similar classifications of the countries of Latin America and the Caribbean, thus supporting the robustness of the results obtained.

\footnotetext{
17 In fact, the meta-analysis conducted by Dolnicar (2003), which includes 243 articles on market segmentation using the cluster analysis technique, reveals that the Ward method is the most popular clustering algorithm used in hierarchical cluster analysis (used in $57 \%$ of cases).
} 


\section{Annex A3}

Table A3.1

Matrix of correlations of the variables used in the analysis

\begin{tabular}{|c|c|c|c|c|c|}
\hline & & Poverty rate & $\begin{array}{l}\text { Share of the } \\
\text { poorest } 40 \%\end{array}$ & $\mathrm{CO}_{2}$ per capita & Control of corruption \\
\hline \multirow[t]{3}{*}{ Poverty rate } & Pearson correlation & 1 & -0.361 & -0.188 & -0.303 \\
\hline & $p$-value & & 0.070 & 0.357 & 0.133 \\
\hline & $\mathrm{N}$ & 26 & 26 & 26 & 26 \\
\hline \multirow[t]{3}{*}{ Share of the poorest $40 \%$} & Pearson correlation & -0.361 & 1 & 0.346 & 0.414 \\
\hline & $p$-value & 0.070 & & 0.084 & 0.036 \\
\hline & $\mathrm{N}$ & 26 & 26 & 26 & 26 \\
\hline \multirow[t]{3}{*}{$\mathrm{CO}_{2}$ per capita } & Pearson correlation & -0.188 & 0.346 & 1 & -0.005 \\
\hline & $p$-value & 0.357 & 0.084 & & 0.980 \\
\hline & $\mathrm{N}$ & 26 & 26 & 26 & 26 \\
\hline \multirow[t]{3}{*}{ Corruption control } & Pearson correlation & -0.303 & 0.414 & -0.005 & 1 \\
\hline & $p$-value & 0.133 & 0.036 & 0.980 & \\
\hline & $\mathrm{N}$ & 26 & 26 & 26 & 26 \\
\hline
\end{tabular}

Source: Prepared by the author. 


\section{Annex A4}

Figure A4.1

Latin America and the Caribbean (26 countries): dendrogram of the classification of the region's countries

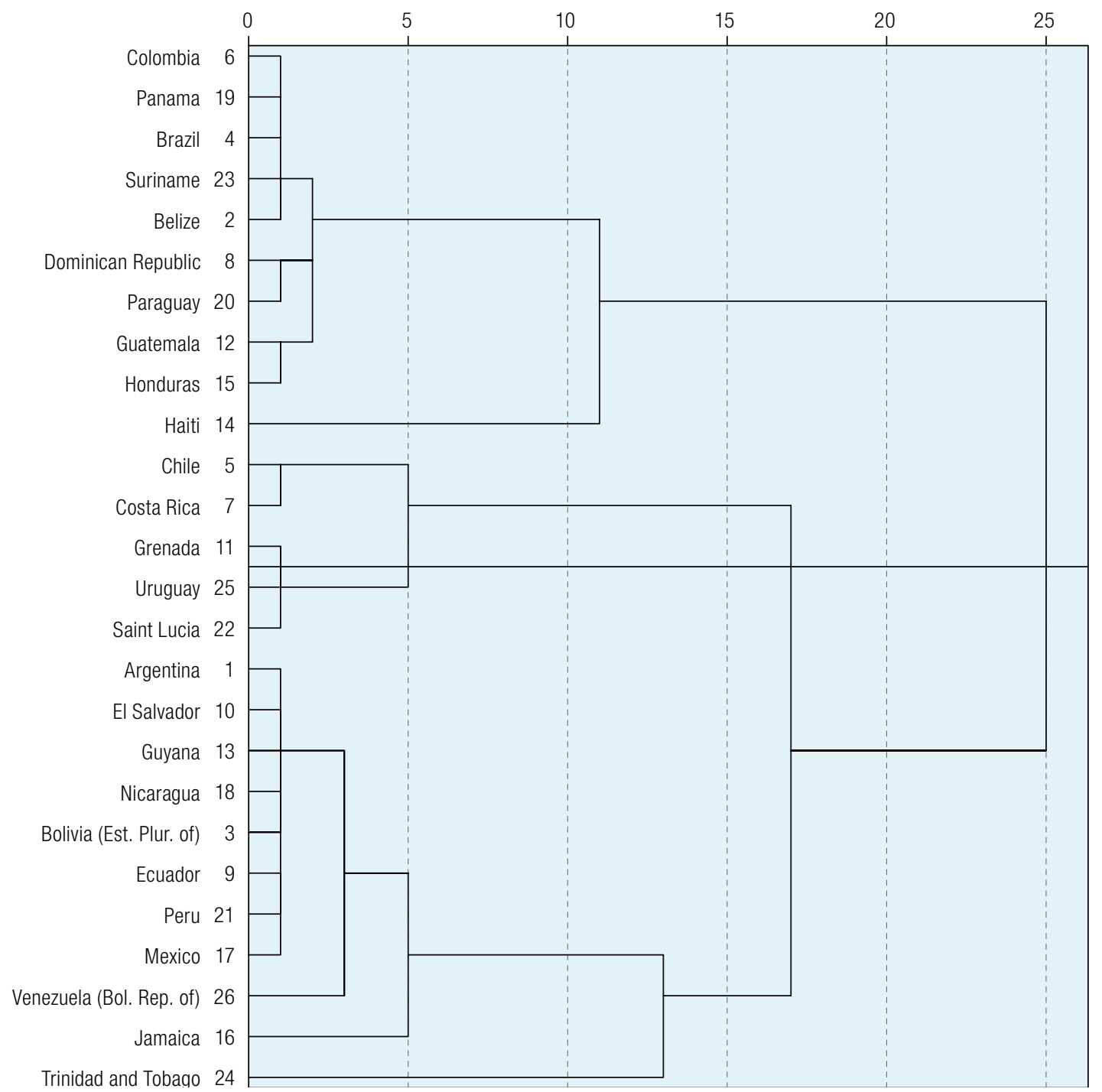

Source: Prepared by the author. 


\section{Annex A5}

Table A5.1

Detailed clustering history

\begin{tabular}{|c|c|c|c|c|c|c|}
\hline \multirow{2}{*}{ Stage } & \multicolumn{2}{|c|}{ Cluster being combined } & \multirow{2}{*}{ Coefficients } & \multicolumn{2}{|c|}{ Stage at which the cluster first appears } & \multirow{2}{*}{ Next stage } \\
\hline & Cluster 1 & Cluster 2 & & Cluster 1 & Cluster 2 & \\
\hline 1 & 9 & 13 & 0.003 & 0 & 0 & 2 \\
\hline 2 & 9 & 20 & 0.011 & 1 & 0 & 9 \\
\hline 3 & 3 & 17 & 0.022 & 0 & 0 & 9 \\
\hline 4 & 4 & 18 & 0.035 & 0 & 0 & 8 \\
\hline 5 & 12 & 14 & 0.050 & 0 & 0 & 18 \\
\hline 6 & 6 & 8 & 0.067 & 0 & 0 & 8 \\
\hline 7 & 1 & 16 & 0.085 & 0 & 0 & 15 \\
\hline 8 & 4 & 6 & 0.118 & 4 & 6 & 13 \\
\hline 9 & 3 & 9 & 0.165 & 3 & 2 & 10 \\
\hline 10 & 3 & 10 & 0.223 & 9 & 0 & 20 \\
\hline 11 & 11 & 23 & 0.284 & 0 & 0 & 14 \\
\hline 12 & 2 & 7 & 0.356 & 0 & 0 & 16 \\
\hline 13 & 4 & 19 & 0.434 & 8 & 0 & 16 \\
\hline 14 & 11 & 21 & 0.548 & 11 & 0 & 17 \\
\hline 15 & 1 & 22 & 0.678 & 7 & 0 & 19 \\
\hline 16 & 2 & 4 & 0.845 & 12 & 13 & 18 \\
\hline 17 & 5 & 11 & 1.126 & 0 & 14 & 23 \\
\hline 18 & 2 & 12 & 1.429 & 16 & 5 & 20 \\
\hline 19 & 1 & 24 & 1.736 & 15 & 0 & 21 \\
\hline 20 & 2 & 3 & 2.179 & 18 & 10 & 22 \\
\hline 21 & 1 & 15 & 2.892 & 19 & 0 & 22 \\
\hline 22 & 1 & 2 & 4.009 & 21 & 20 & 23 \\
\hline 23 & 1 & 5 & 5.728 & 22 & 17 & 0 \\
\hline
\end{tabular}

Source: Prepared by the author. 


\section{Annex A6}

Figure A6.1

Dispersion between distances and the number of clusters

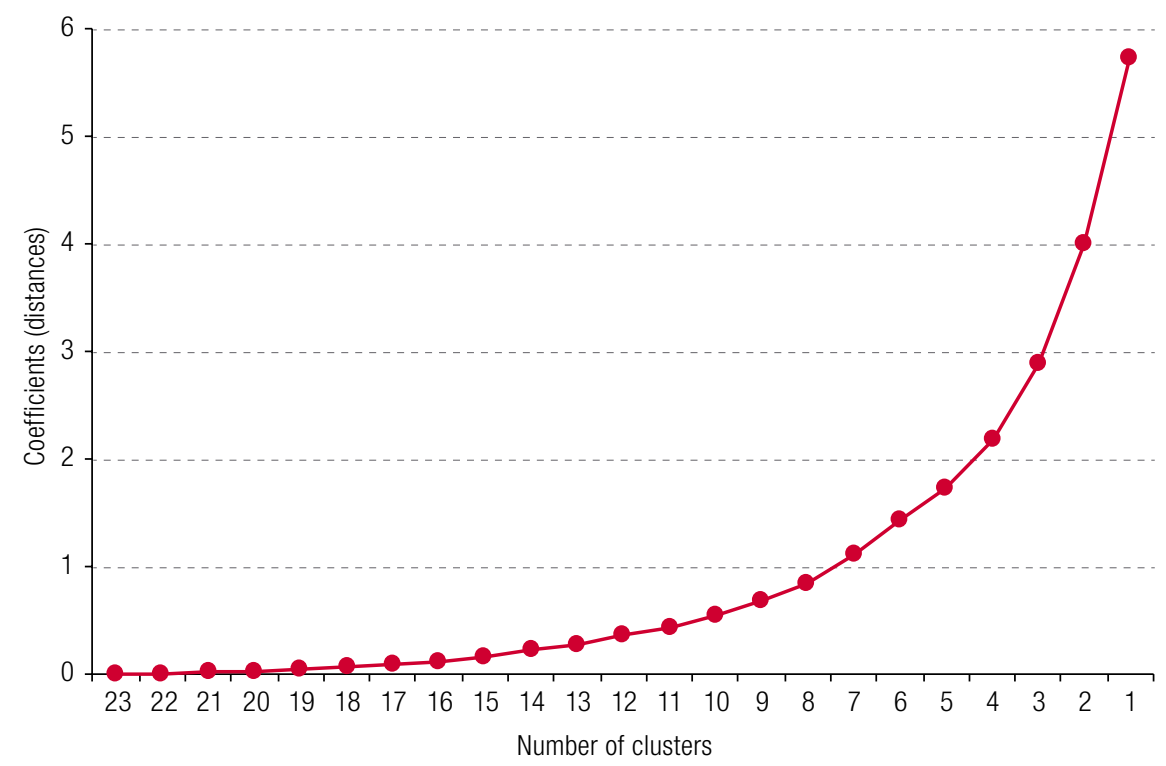

Source: Prepared by the author. 